\title{
Simulation of the Growth of Austenite from As-Quenched Martensite in Medium Mn Steels
}

\author{
FEI HUYAN, JIA-YI YAN, LARS HÖGLUND, JOHN ÅGREN, \\ and ANNIKA BORGENSTAM
}

\begin{abstract}
As part of an ongoing development of third-generation advanced high-strength steels with acceptable cost, austenite reversion treatment of medium Mn steels becomes attractive because it can give rise to a microstructure of fine mixture of ferrite and austenite, leading to both high strength and large elongation. The growth of austenite during intercritical annealing is crucial for the final properties, primarily because it determines the fraction, composition, and phase stability of austenite. In the present work, the growth of austenite from as-quenched lath martensite in medium Mn steels has been simulated using the DICTRA software package. Cementite is added into the simulations based on experimental observations. Two types of systems (cells) are used, representing, respectively, (1) austenite and cementite forming apart from each other, and (2) austenite forming on the cementite/martensite interface. An interfacial dissipation energy has also been added to take into account a finite interface mobility. The simulations using the first type of setup with an addition of interfacial dissipation energy are able to reproduce the observed austenite growth in medium Mn steels reasonably well.
\end{abstract}

https://doi.org/10.1007/s11661-018-4497-3

(c) The Author(s) 2018. This article is an open access publication

\section{INTRODUCTION}

THE austenite reversion treatment of medium $\mathrm{Mn}$ steels (3 to 10 mass pct $\mathrm{Mn}$ ) has gained much attention recently, since the reverted austenite gives rise to both high strength and high elongation. ${ }^{[1]}$ This is aligned with the development of the third-generation advanced high-strength steels with excellent mechanical properties and acceptable cost. ${ }^{[1]}$

The austenite reversion treatment of medium $\mathrm{Mn}$ steels mainly consists of two processes: austenitization and quenching to form martensite, and subsequent intercritical annealing in the ferrite + austenite twophase region for the austenite reversion. ${ }^{[1-11]}$ If growing from as-quenched lath martensite, the reverted austenite is mainly thin-film-like and primarily nucleated at lath boundaries ${ }^{[2,6,7,11]}$ and has almost identical orientations with the prior austenite. ${ }^{[12,13]}$ During intercritical annealing, austenite is mainly stabilized by $\mathrm{C}$ and $\mathrm{Mn}$ partitioning from martensite, meanwhile, martensite gradually becomes ferrite due to $\mathrm{C}$ depletion and dislocation annihilation. ${ }^{[2,5,14]}$ The width of reverted austenite and ferrite/martensite is in the order of a few

FEI HUYAN, JIA-YI YAN, LARS HÖGLUND, JOHN AGREN, ANNIKA BORGENSTAM are with the Department of Materials Science and Engineering, KTH Royal Institute of Technology, 10044 Stockholm, Sweden. Contact e-mail: huyan@kth.se

Manuscript submitted March 8, 2017.

Article published online February 7, 2018 hundred nanometers. Therefore, after intercritical annealing, a fine microstructure of reverted austenite and ferrite/martensite is obtained.

The elongation can be further enhanced, without compromising strength, by exploiting the transformation-induced plasticity (TRIP) effect brought about by the transformation of austenite to martensite under external stress. The TRIP effect is maximized by optimizing the phase stability of austenite. ${ }^{[15,16]}$ The final microstructure and austenite stability of medium Mn steels are determined by the temperature and duration of intercritical annealing. ${ }^{[2,3,9,10,14]}$ Therefore, it is important to understand and model the austenite growth during this process, since an accurate model benefits further steel design.

Many simulations of the austenite reversion from martensite in the Fe-C-Mn and Fe-C-Mn-Si systems can be found in literature. In most of the simulations, a diffusion couple of austenite and martensite is used. ${ }^{[2-4,11,17-21]}$ In this setup, the simulated temporal evolution of austenite volume fraction has three stages, i.e., a rapid increase under non-partitioning local equilibrium (NPLE) controlled by rapid carbon diffusion, a slow increase under partitioning local equilibrium (PLE) controlled by relatively slow diffusion of $\mathrm{Mn}$ in martensite, and a decrease to the equilibrium level under PLE due to homogenization of all alloying elements. When performed on medium Mn steels, such simulations predict much faster austenite formation than experimentally observed after short intercritical 
annealing times, e.g., less than 1 hour, ${ }^{[7,9]}$ primarily attributed to the NPLE stage. In addition, cementite is experimentally observed in these steels during intercritical annealing and could be one of the causes for the discrepancy. In several other simulations, based on the assumption that austenite mainly forms on the cementite/martensite interface, a diffusion couple of martensite and cementite with austenite nucleating in between is used. Nevertheless, these works focus more on cementite dissolution instead of austenite formation, or the steel used has an initial microstructure of ferrite and cementite before intercritical annealing. ${ }^{[21-23]}$

The present simulations focus on the growth of austenite from as-quenched martensite with a lamellar morphology for medium Mn steels during intercritical annealing, taking into account the formation of cementite. Besides, the growth of austenite at the temperature region of intercritical annealing may be controlled by both interface mobility and bulk diffusion of alloying elements. ${ }^{[24]}$ Therefore, it is of interest to study the effect of adding an interfacial dissipation energy (IDE) due to a finite interface mobility to the austenite/martensite interface.

\section{SIMULATION METHOD AND SETUPS}

The kinetic simulations were performed in the DICTRA module of the Thermo-Calc software package, ${ }^{[25-27]}$ using the TCFE7 thermodynamic database and the MOBFE2 mobility database, under local equilibrium at the interfaces. Phase diagrams were calculated using Thermo-Calc with the TCFE7 thermodynamic database as well. The Thermo-Calc software used was Version $2016 \mathrm{~b}$ modified to allow adding an IDE to a specified interface among multiple ones. One-dimensional systems (cells) including martensite $(\alpha)$, austenite $(\gamma)$, and cementite $(\theta)$ in Cartesian coordinates were used to model the planar growth of austenite, representing the thickening of austenite films. Martensite was treated as a body-centered cubic phase supersaturated with C. During intercritical annealing, martensite gradually becomes ferrite, and in the following texts both will be denoted as " $\alpha$ " without distinction. To represent different degrees of martensite tempering prior to austenite reversion, the initial cementite fraction was varied. The initial state without retained austenite was simulated by setting austenite as "inactive" which means that austenite appears when its driving force for precipitation exceeds a prescribed value, $10^{-5} \mathrm{~J} / \mathrm{mol}$.

The setup previously used in the literature which contains only austenite and martensite is named "Setup O" thereafter. When cementite is added to Setup O and the nucleation sites of austenite are considered, two types of setups are constructed according to the microstructure schematically illustrated in Figure 1(a). The first one, named "Setup A," contains regions of austenite, martensite, and cementite from left to right, as shown in Figure 1(b). This setup represents that austenite nucleates on martensite lath boundaries and grows into martensite laths while cementite forms inside martensite laths. The second, "Setup B," consists of regions of cementite, austenite, and martensite from left to right, as shown in Figure 1(c). This setup represents that austenite forms on the cementite/martensite interface. Although cementite is observed as rods, we keep to the planar cell. This is acceptable because our focus is to better describe the growth of austenite instead of accurately simulating the formation or dissolution of cementite. Furthermore, a specific setup will be denoted as, for instance, $0 \gamma 199 \alpha 1 \theta$, meaning the cell initially contains regions of 0 austenite, $199 \mathrm{~nm}$ martensite, and 1 $\mathrm{nm}$ cementite from left to right.

In the simulations where a finite mobility of the $\alpha / \gamma$ interface was considered, the molar IDE, $\Delta G_{\mathrm{m} \text { (diss) }}$, was calculated using

$$
\Delta G_{\mathrm{m}(\mathrm{diss})}=v V_{\mathrm{m}} / M
$$

in which $\mathrm{v}$ is the interface velocity, $V_{\mathrm{m}}$ the molar volume, and $M$ the interface mobility using a description of

$$
M(\mathrm{~m} \mathrm{~mol} / \mathrm{J} \mathrm{s})=0.058 \exp (-140000 / R T)
$$

in which $R$ is the gas constant and $T$ is temperature. ${ }^{[28]}$

Under a simplified treatment, the Gibbs energy of austenite is offset by $\Delta G_{\mathrm{m} \text { (diss) }}$ while local equilibrium is still assumed. ${ }^{[29]}$ It should be mentioned that the above expression for $M$ gives a much lower mobility than what was used in many prior calculations. A lower mobility yields a larger dissipation energy and is thus expected to have a more pronounced effect on the rapid NPLE stage of the transformation.

In addition, $u$-fraction is applied as the composition variables in the simulation, and the $u$-fraction of a component $\mathrm{k}$ is defined as

$$
u_{\mathrm{k}}=\frac{x_{\mathrm{k}}}{\sum x_{\mathrm{S}}}
$$

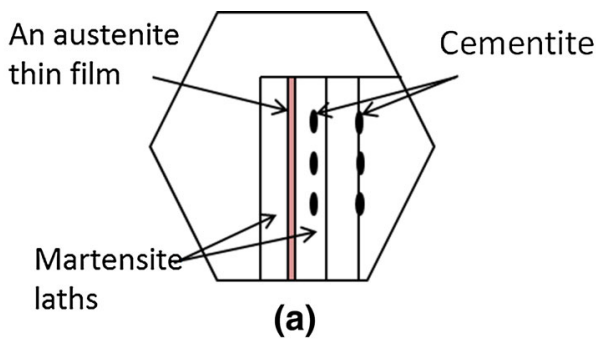

Setup $A-\gamma \alpha \theta$

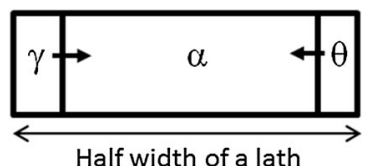

(b)
Setup B - $\theta \gamma \alpha$

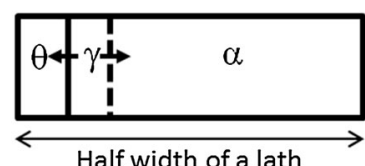

(c)
Fig. 1-(a) Schematic illustration of the microstructure after cementite precipitation during heating, (b) simulation Setup A with regions of austenite, martensite, and cementite corresponding to austenite nucleating far away from cementite, (c) simulation Setup B with regions of cementite, austenite, and martensite corresponding to austenite nucleating on the cementite/martensite interface. 
in which $x_{\mathrm{k}}$ and $x_{\mathrm{S}}$ is the mole fraction of component $\mathrm{k}$ (C or $\mathrm{Mn}$ ) and substitutional element $\mathrm{S}$ (Fe and $\mathrm{Mn}$ ), respectively. It is convenient to use $u$-fraction, since in the present DICTRA simulation it is assumed that only substitutional elements contribute to the volume. ${ }^{[27]}$

\section{RESULTS AND DISCUSSION}

\section{A. Simulations Using Setups $A$ and $B$}

The austenite growth was simulated using Setup A and $\mathrm{B}$ for an Fe- $0.2 \mathrm{C}-5 \mathrm{Mn}$ steel intercritically annealed at $923 \mathrm{~K}\left(650{ }^{\circ} \mathrm{C}\right)$, assuming different initial cementite fractions and martensite lath widths. (Alloying contents are in mass pct and phase fractions are in volume pct, which will be used throughout the texts.) The initial cementite fraction was set to $0.5,1,1.5$, or 2.5 vol pct, respectively. The maximum cementite fraction is about 2.7 vol pct from lever rule if one assumes that all $\mathrm{C}$ is concentrated in cementite. The cell size, corresponding to the half width of martensite lath, was set to 100,200 , or $500 \mathrm{~nm}$.

Figure 2 shows the fractions of austenite and cementite simulated using Setup A in which austenite and cementite form with martensite in between. Most of the simulated austenite fractions have three stages and are similar to the simulations in which martensite and austenite are included without cementite. ${ }^{[5-11]}$ Only in the simulation with the largest cementite fraction, 2.5 vol pct, no plateau corresponding to the NPLE growth is observed, since in this case martensite has such a low $\mathrm{C}$ content and thus is in the PLE region from the beginning. In all simulations, cementite gradually grows to a similar maximum fraction and thereafter dissolves, since cementite is unstable at this temperature for this alloy. From the results of the same cell size $(200 \mathrm{~nm})$, with increasing the initial cementite fraction, less austenite fraction is obtained after the same time; after cementite starts to dissolve, the austenite fractions in different simulations start to become similar. Simulations of different cell sizes show that it takes longer time to achieve the same austenite or cementite fraction in a large cell than in a smaller one, since the former requires a longer diffusion distance. For instance, cementite fully dissolves after about $10^{5} \mathrm{~s}$ in a $500 \mathrm{~nm}$ cell, compared to about $10^{3} \mathrm{~s}$ in a $100 \mathrm{~nm}$ cell.

Figure 3 shows the $\mathrm{Mn}$ profiles in $\mathrm{u}$-fraction, i.e., metal atomic fraction, after different times corresponding to the simulation of $0 \gamma 198 \alpha 2 \theta$ in Figure 2. The growth of austenite starts with C diffusion under NPLE. $\mathrm{Mn}$ does not partition at this stage, and a sharp compositional spike of $\mathrm{Mn}$ is formed accompanying the fast advance of the $\alpha / \gamma$ interface, e.g., after $10^{-6}$ and $10^{-4} \mathrm{~s}$. When the growth mode of austenite changes from NPLE to PLE, Mn starts to partition from martensite to austenite. This process is controlled by $\mathrm{Mn}$ diffusion in martensite. The Mn profile after $1 \mathrm{~s}$ shows an early PLE stage where the Mn content in austenite near the $\alpha / \gamma$ interface $\left(u_{\mathrm{Mn}, \gamma}^{\alpha / \gamma}\right)$ slightly increases, but with time it dramatically increases and therefore a severe gradient forms, e.g., after $10^{2} \mathrm{~s}$. With increasing

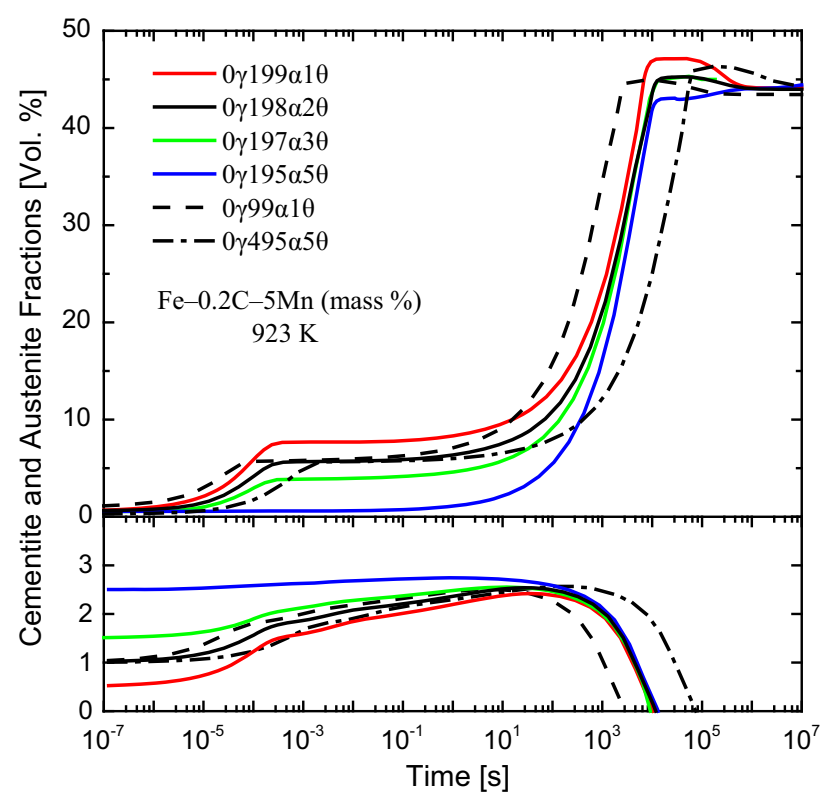

Fig. 2-Simulated austenite and cementite fractions vs time using Setup A with different initial cementite fractions (color-coded solid curves, $200 \mathrm{~nm}$ cell size) or cell sizes (solid and dashed curves in black, 1 vol pct of initial cementite fraction).

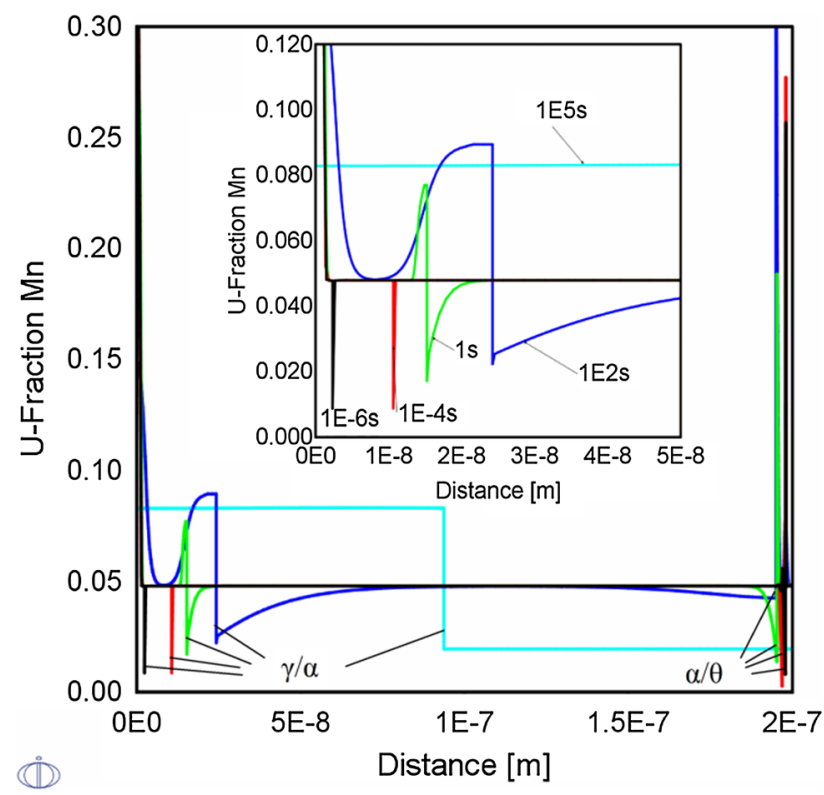

Fig. 3-Mn profiles in u-fraction after different intercritical annealing times $\left(10^{-6}, 10^{-4}, 1,10^{2}\right.$, and $\left.10^{5} \mathrm{~s}\right)$ using Setup A of $0 \gamma 198 \alpha 2 \theta$ $(200 \mathrm{~nm})$

intercritical annealing time, such a gradient gradually levels out and the composition approaches equilibrium, e.g., after $10^{5} \mathrm{~s}$. Cementite forms on the right side of the cell near $200 \mathrm{~nm}$. From $10^{-6}$ to $10^{2} \mathrm{~s}$, cementite grows with the $\alpha / \theta$ interface advancing towards left. Compositional spikes of $\mathrm{Mn}$ at the $\alpha / \theta$ interface are high and sharp due to a high solubility of $\mathrm{Mn}$ in cementite. According to Figure 2, cementite fully dissolves after 
about $10^{4} \mathrm{~s}$, therefore the $\alpha / \theta$ interface is not observed in the composition profile at $10^{5} \mathrm{~s}$.

Figure 4 shows the fractions of austenite and cementite simulated using Setup B in which austenite nucleates on the cementite/martensite interface. In this case, austenite appears and grows after cementite starts to dissolve, and this is a distinct difference from Setup A in which austenite appears and grows from the start of the simulation. When using different initial cementite fraction and the same cell size, i.e., $200 \mathrm{~nm}$, cementite grows from different initial values to the same maximum amount, and thereafter the fractions of austenite and cementite are, respectively. overlapped. This indicates that a difference in initial cementite fraction has a negligible influence on the fractions of austenite and cementite. When the cell size is increased from 100 to $500 \mathrm{~nm}$, longer time is required to achieve the same austenite fraction.

Figure 5 shows the Mn profiles corresponding to the simulation of $2 \theta 0 \gamma 198 \alpha$ in Figure 4. Cementite starts to form controlled by the rapid $\mathrm{C}$ diffusion without $\mathrm{Mn}$ partition, resulting in a compositional spike of $\mathrm{Mn}$ accompanying the advance of the $\alpha / \theta$ interface, $e . g$., after $10^{-6}$ and $10^{-4} \mathrm{~s}$. Thereafter, austenite starts to form and the $\alpha / \theta$ interface splits into a $\theta / \gamma$ and an $\alpha / \gamma$ interface. These two interfaces move in opposite directions, with austenite growing while cementite and martensite are shrinking. The Mn profile after $1 \mathrm{~s}$ shows an early stage after austenite formation. $u_{\mathrm{Mn}, \gamma}^{\alpha / \gamma}$ does not change much with time, thus a less severe Mn gradient in $\gamma$ is observed near the $\alpha / \gamma$ interface, e.g., after $10^{2}$ and $10^{5} \mathrm{~s}$

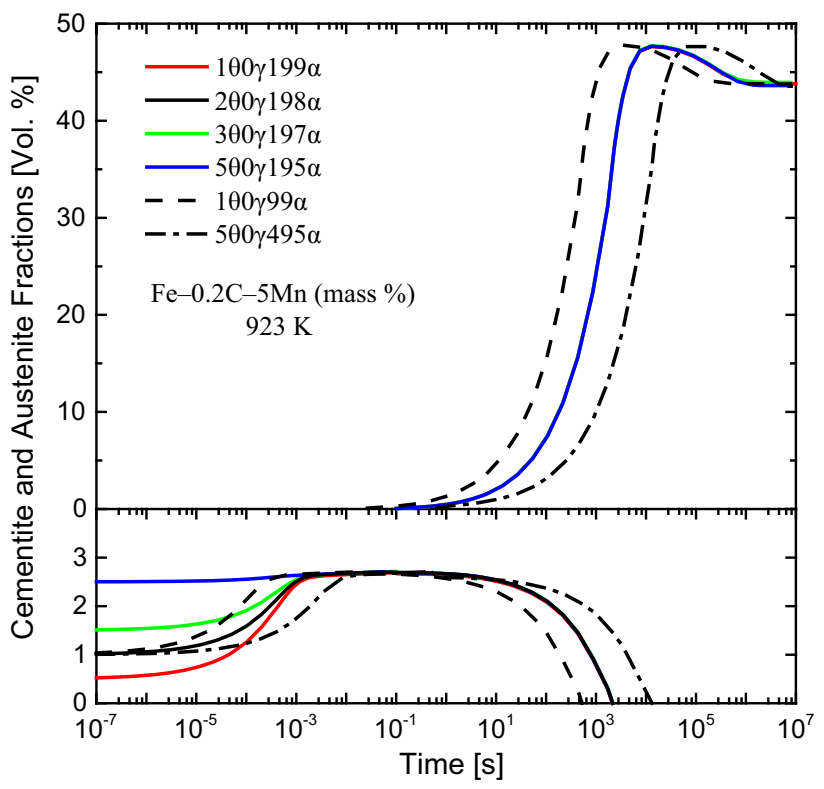

Fig. 4 - Simulated austenite and cementite fractions versus time using Setup B with different initial cementite fractions (color-coded solid curves, $200 \mathrm{~nm}$ cell size) or cell sizes (solid and dashed curves in black, 1 vol pct of initial cementite fraction). Notice that after about $10^{-1} \mathrm{~s}$, the fractions of austenite and cementite using the same cell size $(200 \mathrm{~nm})$, respectively, overlap.

\section{B. Thermodynamics of Setups $A$ and $B$}

As shown in the previous section, the simulation results are quite different using the two setups, which can be understood from thermodynamics.

Figure 6 shows an isothermal section of the Fe-C-Mn phase diagram at $923 \mathrm{~K}\left(650{ }^{\circ} \mathrm{C}\right)$ with the metastable $\alpha / \gamma$ and $\alpha / \theta$ phase boundaries to illustrate the kinetics of Setup A. When $\gamma$ starts to form under NPLE, the $\alpha$ and $\gamma$ compositions at the $\alpha / \gamma$ interface do not change during the NPLE stage, with the corresponding tie-line marked as 1 in Figure 6. After the growth mode changes from NPLE to PLE, the tie-line moves in the direction marked as 2 in the phase diagram, therefore $\mathrm{u}_{\mathrm{Mn}, \gamma}^{\alpha / \gamma}$ increases with time during PLE. Cementite grows from the start of the simulation as well. The $\alpha$ and $\theta$ compositions at the $\alpha / \theta$ interface follow the tie-line of $\alpha /$ $\theta$ boundary (not shown in Figure 6).

Figure 7 shows an isothermal section of the Fe-C-Mn phase diagram at $923 \mathrm{~K}\left(650^{\circ} \mathrm{C}\right)$ with equilibria among $\alpha, \gamma$, and $\theta$ to illustrate the kinetics of Setup B. The growth of $\theta$ also starts under NPLE, and at this stage the $\alpha$ and $\theta$ compositions at the $\alpha / \theta$ interface follow the tie-line marked as 1 in the $\alpha+\theta$ region. When the growth of $\theta$ has changed to PLE, the tie-line starts to move towards the direction marked as 2 . When the tie-line reaches the three phase triangle (in red), austenite starts to form and the $\alpha / \theta$ interface splits into an $\alpha / \gamma$ and a $\theta / \gamma$ interface. Thereafter, marked as 3 , the $\alpha / \gamma$ and the $\theta / \gamma$ interfaces evolve according to their own tie-lines, respectively, and these two separate tie-lines are connected by the $\mathrm{C}$ iso-activity line in $\gamma$. When austenite forms, $u_{\mathrm{Mn}, \gamma}^{\alpha / \gamma}$ is about 0.08 , and it slightly varies with time, thus no severe Mn gradient in $\gamma$ is observed near the $\alpha / \gamma$ interface.

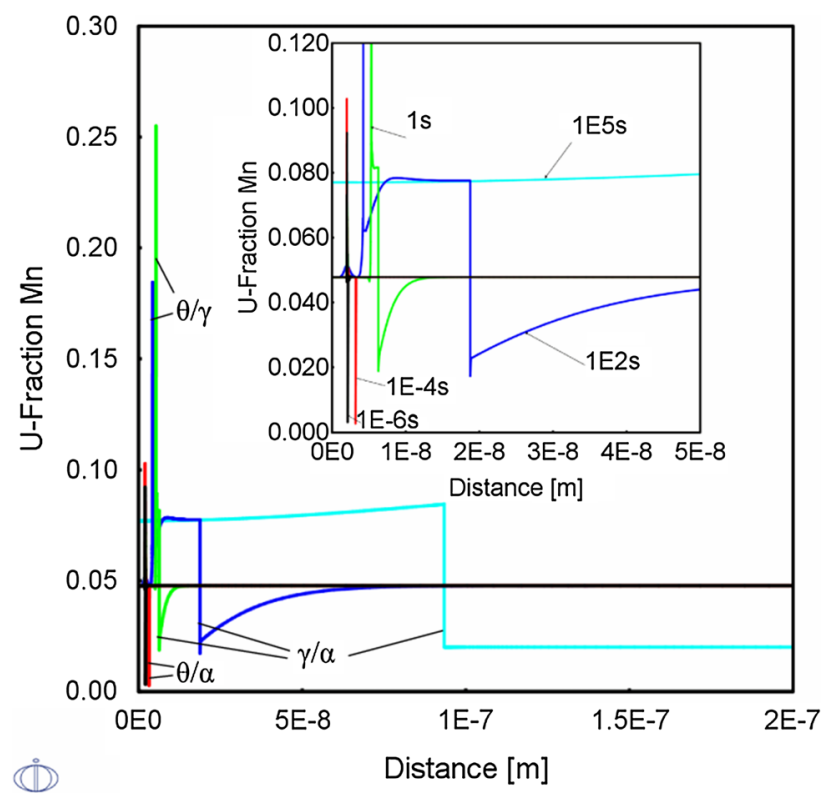

Fig. 5- Mn profiles in u-fraction after different intercritical annealing times $\left(10^{-6}, 10^{-4}, 1,10^{2}\right.$, and $\left.10^{5} \mathrm{~s}\right)$ using Setup B of $2 \theta 0 \gamma 198 \alpha$ $(200 \mathrm{~nm})$ 


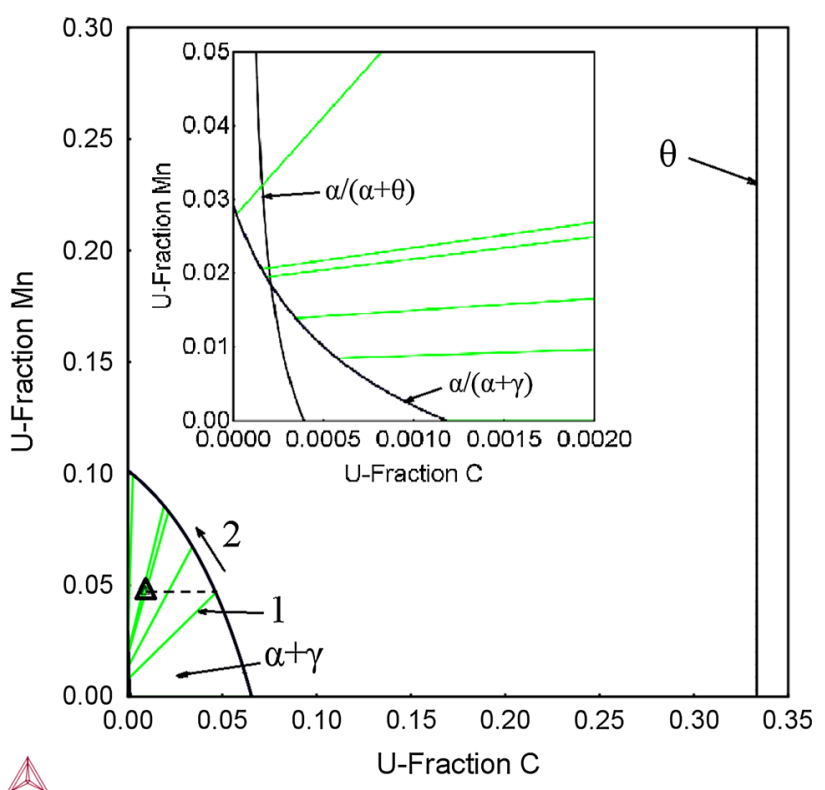

Fig. 6-An isothermal section of the Fe-C-Mn phase diagram at 923 $\mathrm{K}\left(650{ }^{\circ} \mathrm{C}\right)$ showing the metastable $\alpha / \gamma$ and $\alpha / \theta$ phase boundaries. The triangle represents the overall composition of the studied alloy, Fe- $0.2 \mathrm{C}-5 \mathrm{Mn}$.

\section{Simulations with Addition of an IDE}

The simulations using Setups A and B in the previous section are based on the assumptions that the transformation is controlled by bulk diffusion of alloying elements and that the interface has an infinitely high mobility. In this section, we discuss the influence of adding an IDE to the $\alpha / \gamma$ interface due to a finite interface mobility where the interfacial condition deviates from local equilibrium.

Figure 8 shows a comparison of simulations using Setup A with and without addition of an IDE described by Eqs. [1] and [2] for an Fe-0.2C-5Mn steel intercritically annealed at $923 \mathrm{~K}\left(650{ }^{\circ} \mathrm{C}\right)$. In these simulations, the cells contain $1 \mathrm{~nm}$ austenite on the left, since the addition of an IDE requires a specified interface. Besides, the simulation results using $1 \gamma 198 \alpha 1 \theta$ and $0 \gamma 199 \propto 1 \theta$ are very similar, which are not shown here. With addition of the IDE, the growth of austenite is suppressed initially, and the plateau corresponding to the transition of NPLE/PLE disappears. If the mobility is increased 10 times, the IDE decreases to $1 / 10$, and a slight plateau is observed.

The effect of addition of IDE on the $\alpha / \gamma$ interface velocity is shown in Figure 9. In Setup A, the growth of austenite starts with a high velocity of about $10^{-2} \mathrm{~m} / \mathrm{s}$, which decreases to $10^{-6} \mathrm{~m} / \mathrm{s}$ after about $10^{-3} \mathrm{~s}$ in the NPLE stage, followed by an even lower velocity from about $10^{-8}$ to $10^{-14} \mathrm{~m} / \mathrm{s}$ under PLE. The addition of an IDE to Setup A reduces the interface velocity under NPLE by several orders to about $10^{-6} \mathrm{~m} / \mathrm{s}$, while the velocity under PLE is almost unaffected. In Setup B, austenite starts to form after about $10^{-1} \mathrm{~s}$ under PLE, and thereafter the velocity is almost identical to the velocity from Setup A. Since the IDE is proportional to the interface velocity, the absence of an NPLE stage

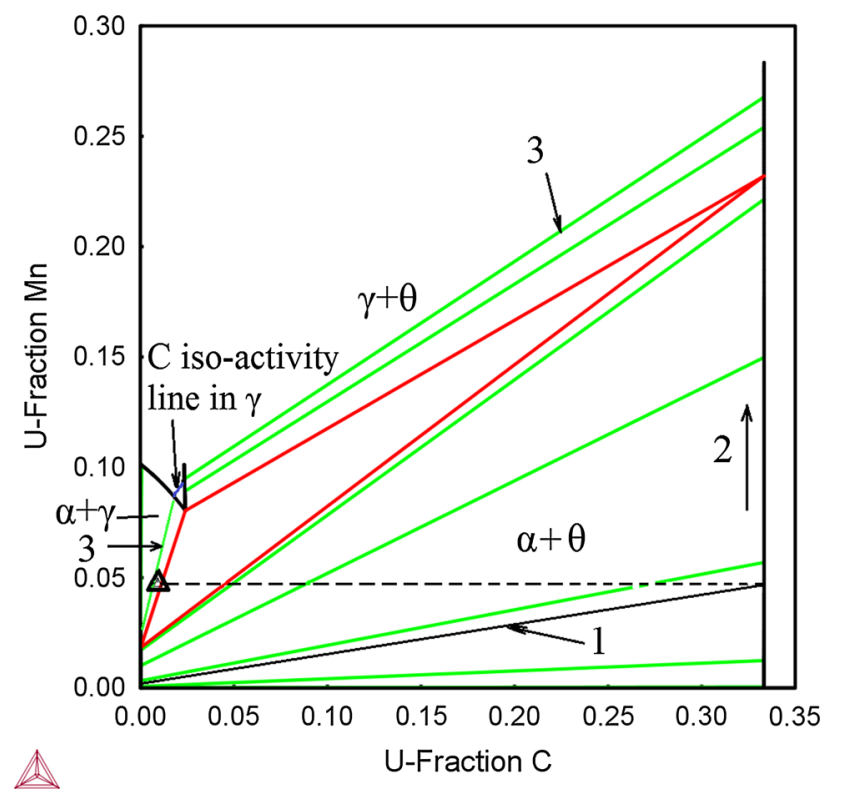

Fig. 7-An isothermal section of the Fe-C-Mn phase diagram at 923 $\mathrm{K}\left(650^{\circ} \mathrm{C}\right)$ showing equilibria among $\alpha, \gamma$, and $\theta$. The black triangle represents the overall composition of the studied alloy, $\mathrm{Fe}-0.2 \mathrm{C}-5 \mathrm{Mn}$.

makes the addition of an IDE negligible in Setup B. Therefore, the IDE is unnecessary to add to setup B.

\section{Comparison with Experimental Data}

The austenite reversion in an Fe-0.2C-4.7Mn steel has been studied in detail by Luo and coworkers, ${ }^{[2]}$ and these experimental data will be adapted as a first comparison to the present setups. The steel has an initial microstructure of as-quenched lath martensite without cementite. It was intercritically annealed at 923 $\mathrm{K}\left(650{ }^{\circ} \mathrm{C}\right)$ with a heating rate of about 40 to $60 \mathrm{~K} / \mathrm{s}$ $\left({ }^{\circ} \mathrm{C} / \mathrm{s}\right)$. After intercritical annealing, the reverted austenite is mainly thin-film-like. Simulations were performed using Setups O, A, B, and A with an addition of IDE ("A + M") described by Eqs. [1] and [2]. The cell sizes were set to $200 \mathrm{~nm}$, which was half of the experimentally measured average thickness of martensite laths. The simulation results are shown in Figures 10 and 11, compared with experimental data.

As shown in Figure 10, the austenite fractions for Setups $\mathrm{O}$ and $\mathrm{A}$ show a plateau corresponding to the transition of NPLE/PLE, and reach about 20 and 7.5 vol pet after about $10^{-3} \mathrm{~s}$, respectively. Due to such plateaus, the simulated austenite fractions are much higher than the experimental data after short times, e.g., $10^{2} \mathrm{~s}$. The results from Setup A $+\mathrm{M}$ and Setup B agree quite well with the experimental data in the start up to about $10^{3} \mathrm{~s}$, and thereafter are slightly higher. In the later stage after about $2 \times 10^{4} \mathrm{~s}$, the experimental austenite fraction decreases with time and is persistently lower than the calculated value. An explanation could be that austenite partly transforms to martensite during the final cooling after intercritical annealing. This will be described in detail further on. 


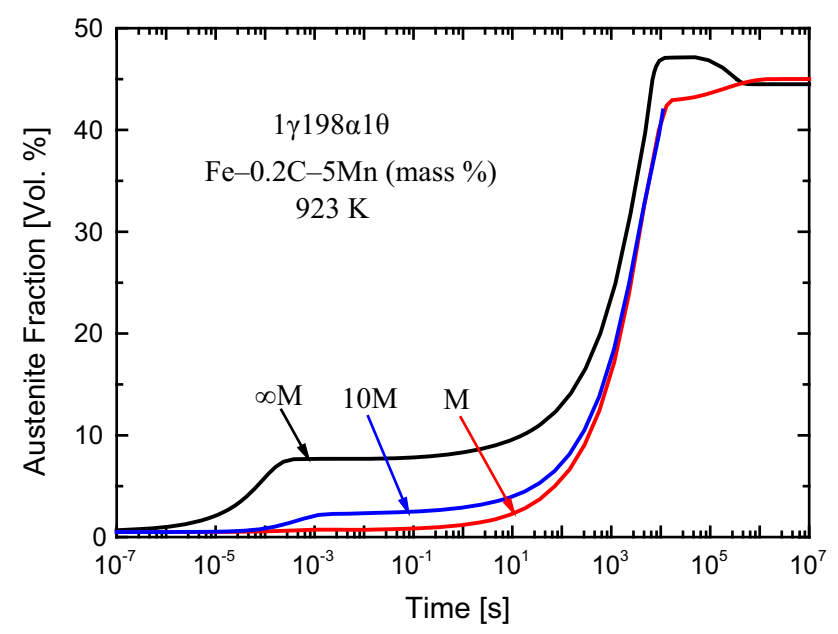

Fig. 8-Comparison of the growth of austenite using Setup A with an infinitely high interface mobility $(\infty \mathrm{M})$ and with an IDE using the interface mobility given by Eq. [2] $(M)$ or an interface mobility 10 times larger $(10 M)$.

Regarding the austenite composition, as shown in Figure 11, the simulated $\mathrm{C}$ content in austenite from Setups $\mathrm{O}, \mathrm{A}$, and $\mathrm{A}+\mathrm{M}$ exhibits a peak followed by a basin before reaching the final equilibrium. This is mainly due to the competition between the increase of $\mathrm{C}$ content in austenite due to partitioning and the increase of austenite fraction. Especially in the simulation using Setup $\mathrm{A}+\mathrm{M}$, the $\mathrm{C}$ content increases drastically in the beginning because austenite grows much slower and becomes much more $\mathrm{C}$ enriched than without addition of the IDE. It is noteworthy that the basin of $\mathrm{C}$ content between $10^{1}$ and $10^{4} \mathrm{sec}$ in Setups $\mathrm{A}$ and $\mathrm{A}+\mathrm{M}$ is associated with the formation and dissolution of cementite. In contrast, the $\mathrm{C}$ content in Setup $\mathrm{B}$ keeps relatively stable after the austenite formation. Compared with the experimental data, the results using Setups A, B, and A + M show similar trends, yet they are relatively lower. This may be due to the experimental method that the $\mathrm{C}$ contents were estimated based on lattice parameter determined using XRD. It has been shown that in a quenching and partitioning steel, the $\mathrm{C}$ contents in austenite obtained using atom probe tomography were relatively lower than those determined using XRD based on the same formula of lattice parameter and composition as in the work from Luo et al. ${ }^{[2,30]}$

The experimental $\mathrm{Mn}$ content in austenite shows a slight increase even though the experimental scatters are large, and such an increase could be comparable with Setups O, A, and A + M, while it is different from Setup $\mathrm{B}$ in which the simulated $\mathrm{Mn}$ content keeps approximately constant.

Since austenite and cementite form competitively at the expense of martensite, either Setup A or B can be operative in reality. A recent work based on the orientation relationship among reverted austenite, martensite, and cementite concluded that, the formation of thin-film-like retained austenite is attributed to a strong variant selection by the surrounding martensite, while nucleation of austenite at cementite/martensite

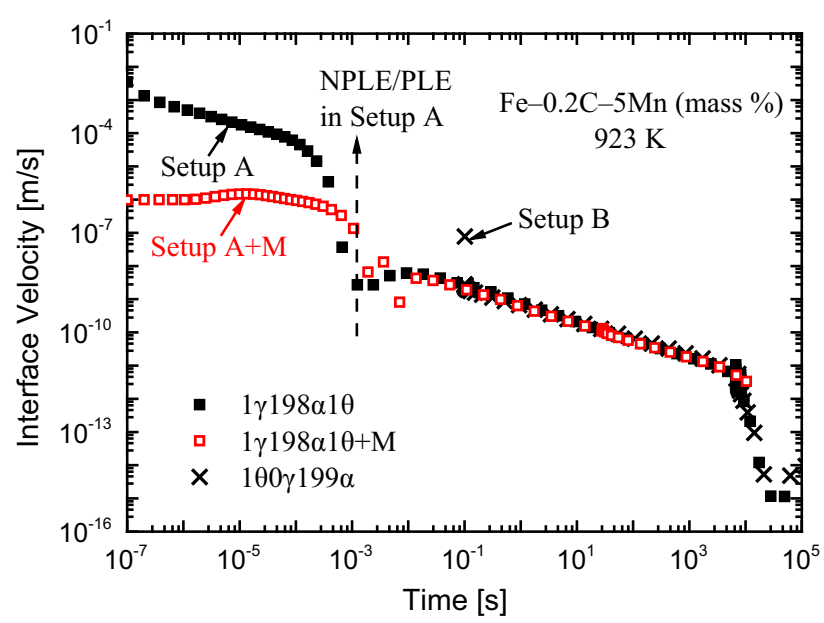

Fig. 9-The velocity of the $\alpha / \gamma$ interface versus time. Solid and hollow squares are from Setup A without and with addition of an IDE, respectively. The crosses are from Setup B. Notice that the three groups of data overlap after about $10^{-1} \mathrm{~s}$.

interface weakens the variant selection and this leads to the formation of intra-granular globular austenite. ${ }^{[12]}$ Therefore, Setups A and B could be related to a thin-film-like and a globular morphology, respectively. Generally, the selection of Setup A or B to simulate austenite reversion depends on the final microstructure, i.e., which morphology of reverted austenite is dominant, and this can be estimated according to the initial microstructure, annealing temperature, heating rate, etc. In order for Setup A to be realistic, the lamellar structure should be maintained. Setup A seems more relevant if the initial microstructure mostly contains martensite laths. A high heating rate is preferred since the tempering of martensite is minimal and thus only a small amount of austenite is formed. Setup B may be more relevant if the initial microstructure is mainly tempered martensite or the heating rate is relatively low, such that reverted austenite has to re-nucleate, most likely on the martensite/cementite interface.

Regarding the fraction and composition of austenite presented in Figures 10 and 11 as well as the discussion above, the simulations using Setup $\mathrm{A}+\mathrm{M}$ agree rather well with experimental data of $\mathrm{Fe}-0.2 \mathrm{C}-4.7 \mathrm{Mn}$ at $923 \mathrm{~K}$ $\left(650^{\circ} \mathrm{C}\right)$. Therefore, Setup A $+\mathrm{M}$ is applied to the same steel intercritically annealed at two other temperatures as well as several other steels. The simulated austenite fractions are compared to experimental data from the literature ${ }^{[8,9,18,19]}$ in Figure 12. In all simulations, a 200 $\mathrm{nm}$ cell with $1 \mathrm{~nm}$ cementite is adopted since no experimental information on the microstructure is provided by the references. For the Fe-0.2C-7Mn steel, the microstructure initially contained about 10 vol pct austenite according to the experimental observation, ${ }^{[9]}$ which was taken into account in the simulation as shown in Figure 12(c), i.e., the cell contains $20 \mathrm{~nm}$ austenite on the left. All the simulated austenite fractions can reproduce the experimental data reasonably well before the experimental austenite fraction starts to decrease.

The decreases of the experimental austenite fractions in Figures 10 and 12(a), (c) are due to transformation of 


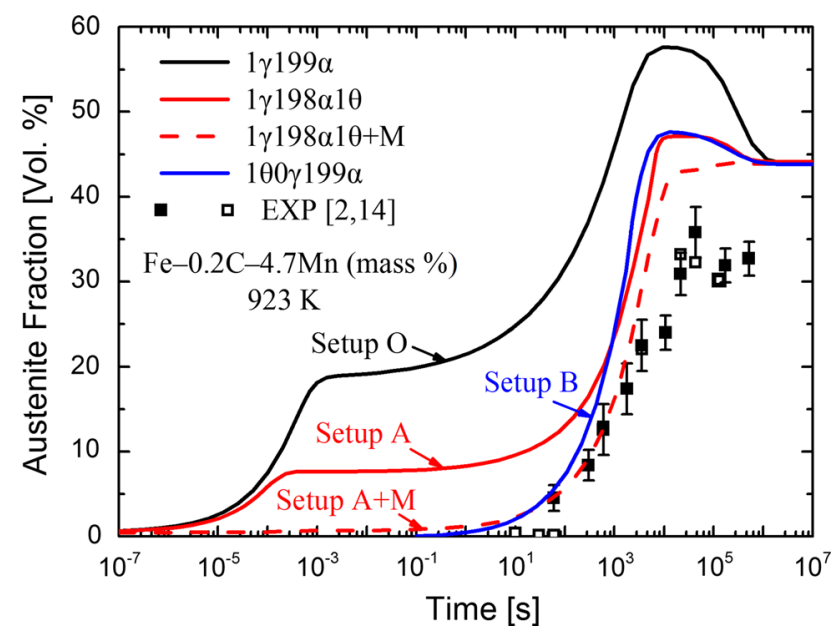

Fig. 10-Comparison of simulated austenite fraction according to different setups compared with experimental data of an $\mathrm{Fe}-0.2 \mathrm{C}-4.7 \mathrm{Mn}$ steel intercritically annealed at $923 \mathrm{~K}\left(650{ }^{\circ} \mathrm{C}\right) .{ }^{[2,14]}$

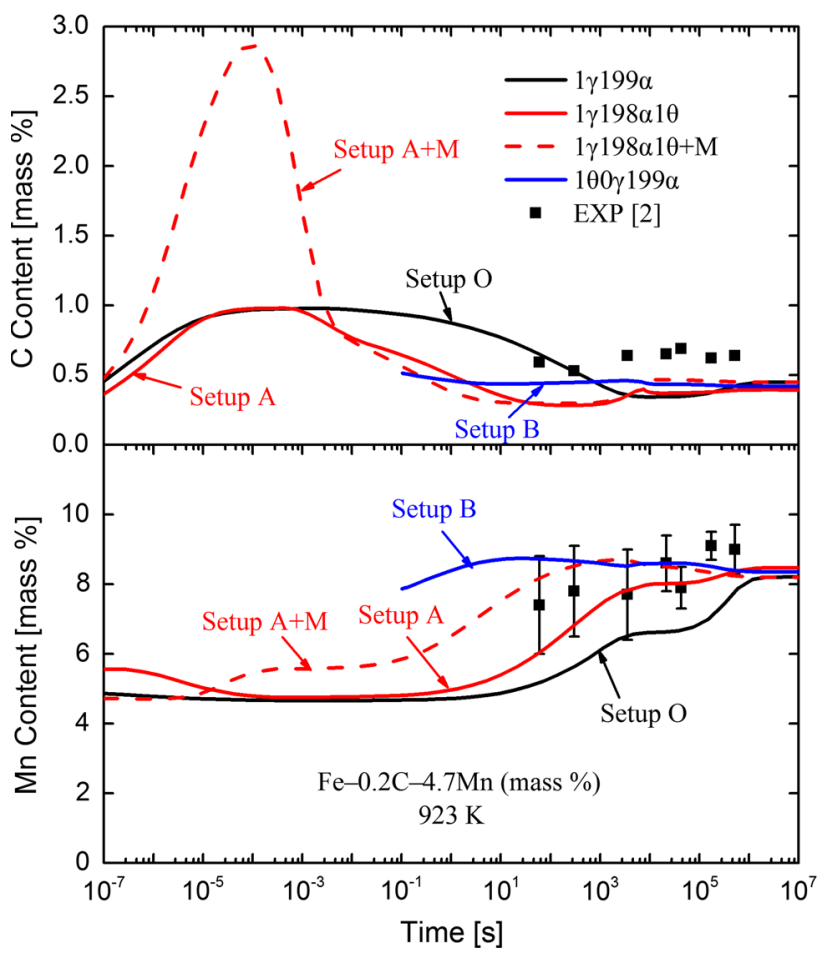

Fig. 11-Comparison of simulated $\mathrm{C}$ and $\mathrm{Mn}$ content in austenite according to different setups compared with experimental data of an $\mathrm{Fe}-0.2 \mathrm{C}-4.7 \mathrm{Mn}$ steel intercritically annealed at $923 \mathrm{~K}\left(650^{\circ} \mathrm{C}\right) .{ }^{[2]}$

austenite to martensite upon the final cooling after intercritical annealing. This is supported by microstructure characterizations and hardness data. ${ }^{[9,14]}$ To predict the final austenite fraction in this case, the transformation to martensite needs to be taken into account by predicting the martensite-start temperature of the austenite and the fraction of newly formed martensite below the martensite-start temperature, which is beyond the scope of this paper.

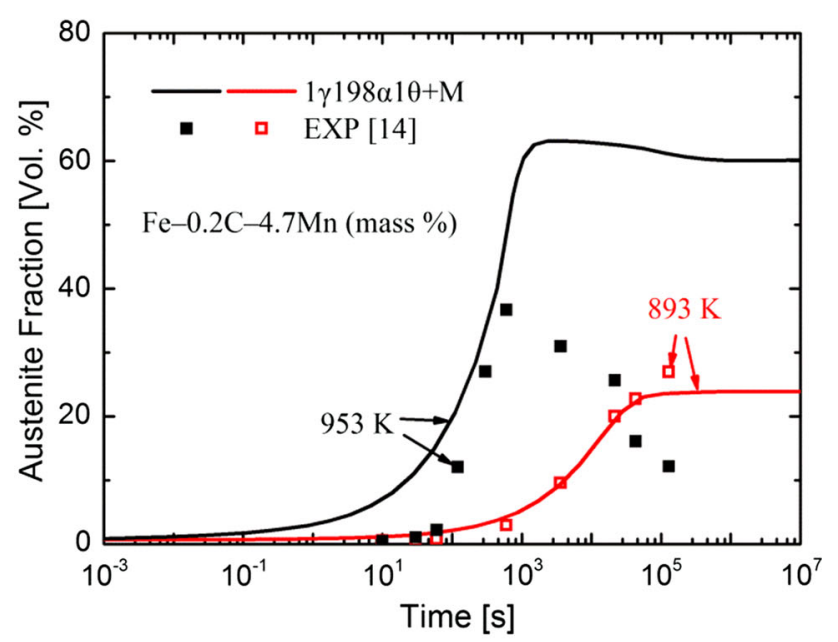

(a)

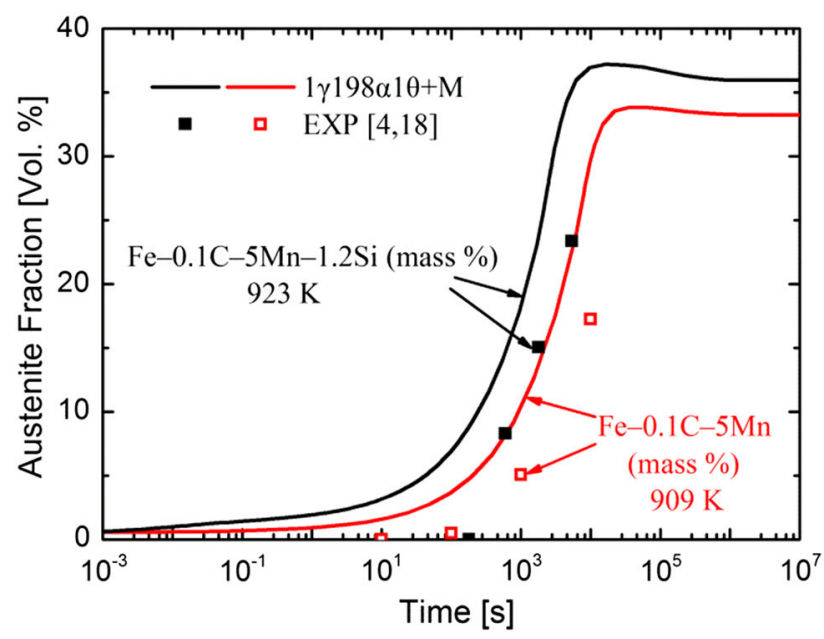

(b)

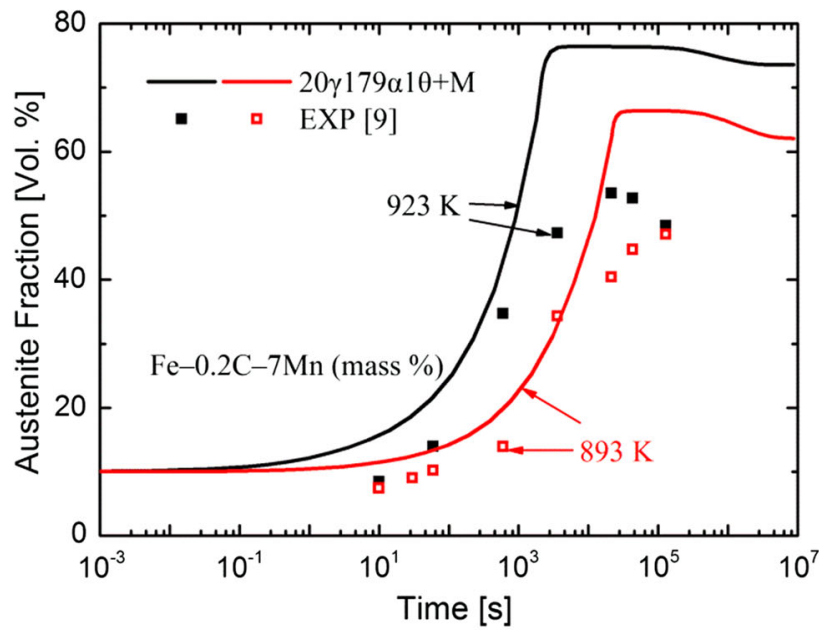

(c)

Fig. 12- Simulated austenite fraction versus time using Setup A + M compared with the experimental results after intercritical annealing of $(a)$ an $\mathrm{Fe}-0.2 \mathrm{C}-4.7 \mathrm{Mn}$ steel at $893 \mathrm{~K}$ and $953 \mathrm{~K}(620$ and $\left.680{ }^{\circ} \mathrm{C}\right),{ }^{[14]}(b)$ an $\mathrm{Fe}-0.1 \mathrm{C}-5 \mathrm{Mn}$ steel at $909 \mathrm{~K}\left(636^{\circ} \mathrm{C}\right)$ and an $\mathrm{Fe}-0.1 \mathrm{C}-5 \mathrm{Mn}-1.2 \mathrm{Si}$ steel at $923 \mathrm{~K}\left(650{ }^{\circ} \mathrm{C}\right),{ }^{[4,18]}$ and $(c)$ an $\mathrm{Fe}-0.2 \mathrm{C}-7 \mathrm{Mn}$ steel at $893 \mathrm{~K}$ and $923 \mathrm{~K}\left(620\right.$ and $\left.650{ }^{\circ} \mathrm{C}\right) \cdot{ }^{[9]}$ 


\section{SUMMARY}

In the present study, the growth of austenite from as-quenched lath martensite in medium Mn steels during intercritical annealing has been simulated using the DICTRA software package. Simulations using a cell of austenite and martensite (Setup O) show three temporal stages of austenite fraction: a rapid growth under non-partitioning local equilibrium (NPLE), a slow growth under partitioning local equilibrium (PLE), and a shrinkage under PLE until equilibrium is reached. Experimental observations motivate an addition of cementite in the simulations. Two setups of simulation cells are used to represent different nucleation sites of austenite: an austenite-martensite-cementite cell (Setup A) corresponding to austenite and cementite forming apart from each other, and a cementite-austenite-martensite cell (Setup B) corresponding to austenite forming on the cementite/martensite interface. In Setup A, austenite fraction evolves in the same three stages as in Setup O, while in Setup B austenite enters the PLE stage directly once it appears. In Setup A, the Mn content in austenite increases over time, while in Setup B it is approximately constant. A dissipation energy is further added to the austenite/martensite interface to take into account the effect of a finite interface mobility. In Setup A, the interfacial dissipation suppresses the rapid growth under NPLE condition, while it is not effective in Setup B because of an absence of a rapid growth. The applicability of Setups A and B is discussed. When compared to experimental data, simulations using Setup A with addition of an austenite/martensite interfacial dissipation energy can reproduce the growth of austenite in medium Mn steels rather well.

\section{ACKNOWLEDGMENTS}

This work was performed within the VINN Excellence Center Hero-m, financed by VINNOVA (the Swedish Governmental Agency for Innovation Systems), Swedish industry, and KTH Royal Institute of Technology.

\section{OPEN ACCESS}

This article is distributed under the terms of the Creative Commons Attribution 4.0 International License (http://creativecommons.org/licenses/by/4.0/), which permits unrestricted use, distribution, and reproduction in any medium, provided you give appropriate credit to the original author(s) and the source, provide a link to the Creative Commons license, and indicate if changes were made.

\section{REFERENCES}

1. Y.-K. Lee and J. Han: Mater. Sci. Technol., 2015, vol. 31, pp. 843-56.

2. H. Luo, J. Shi, C. Wang, W. Cao, X. Sun, and H. Dong: Acta Mater., 2011, vol. 59, pp. 4002-14.

3. S. Lee and B.C. De Cooman: Metall. Mater. Trans. A Phys. Metall. Mater. Sci., 2013, vol. 44, pp. 5018-24.

4. T. Tsuchiyama, T. Inoue, J. Tobata, D. Akama, and S. Takaki: Scr. Mater., 2016, vol. 122, pp. 36-9.

5. S.J. Lee, S. Lee, and B.C. De Cooman: Scr. Mater., 2011, vol. 64, pp. 649-52.

6. J. Han, S.J. Lee, J.-G. Jung, and Y.K. Lee: Acta Mater., 2014, vol. 78, pp. 369-77.

7. R.L. Miller: Metall. Trans., 1972, vol. 3, pp. 905-12.

8. B.B. He, B. Hu, H.W. Yen, G.J. Cheng, Z.K. Wang, H.W. Luo, and M.X. Huang: Science (80-.)., 2017, vol. 357, pp. 1029-32.

9. C. Zhao, C. Zhang, W. Cao, and Z. Yang: Int. J. Miner. Metall. Mater., 2016, vol. 23, pp. 161-7.

10. S. Kang, J.G. Speer, D. Krizan, D.K Matlock, and E. De Moor: Mater. Des., 2016, vol. 97, pp. 138-46.

11. R. Wei, M. Enomoto, R. Hadian, H.S. Zurob, and G.R. Purdy: Acta Mater., 2013, vol. 61, pp. 697-707.

12. X. Zhang, G. Miyamoto, Y. Toji, S. Nambu, T. Koseki, and T. Furuhara: Acta Mater., 2018, vol. 144, pp. 601-12.

13. N. Nakada, T. Tsuchiyama, S. Takaki, and S. Hashizume: ISIJ Int., 2007, vol. 47, pp. 1527-32.

14. C. Zhao, W.Q. Cao, C. Zhang, Z.G. Yang, H. Dong, and Y.Q. Weng: Mater. Sci. Technol., 2014, vol. 30, pp. 791-9.

15. G.B. Olson and Z.D. Feinberg: Phase Transform. Steels, 2012, vol. 2, pp. 59-82.

16. Y. Tian, O.I. Gorbatov, A. Borgenstam, A.V. Ruban, and P. Hedström: Metall. Mater. Trans. A Phys. Metall. Mater. Sci., 2017, vol. 48, pp. 1-7.

17. J. Ågren: Acta Metall., 1982, vol. 30, pp. 841-51.

18. N. Nakada, K. Mizutani, T. Tsuchiyama, and S. Takaki: Acta Mater., 2013, vol. 65, pp. 251-8.

19. H. Farahani, W. Xu, and S. van der Zwaag: Metall. Mater. Trans. A Phys. Metall. Mater. Sci., 2015, vol. 46, pp. 4978-85.

20. H. Kamoutsi, E. Gioti, G.N. Haidemenopoulos, Z Cai, and H Ding: Metall. Mater. Trans. A Phys. Metall. Mater. Sci., 2015, vol. 46, pp. 4841-6.

21. H. Luo, J. Liu, and H. Dong: Metall. Mater. Trans. A, 2016, vol. 47, pp. 3119-24.

22. A. Arlazarov, M. Gouné, A. Hazotte, O. Bouaziz, and F. Kegel: Int. Conf. Solid-Solid Phase Transform. Inorg. Mater. (PTM 2015), 2015, p. 8 .

23. J. Emo, P. Maugis, and A. Perlade: Comput. Mater. Sci., 2016, vol. 125 , pp. 206-17.

24. F. Moszner, E. Povoden-Karadeniz, S. Pogatscher, P.J. Uggowitzer, Y. Estrin, S.S.A. Gerstl, E. Kozeschnik, and J.F. Löffler: Acta Mater., 2014, vol. 72, pp. 99-109.

25. J.O. Andersson, T. Helander, L. Höglund, P. Shi, and B. Sundman: Calphad Comput. Coupling Phase Diagrams Thermochem., 2002, vol. 26, pp. 273-312.

26. A. Borgenstam, L. Höglund, J. Agren, and A. Engström: J. Phase Equilib., 2000, vol. 21, pp. 269-80.

27. H. Larsson and L. Höglund: Calphad Comput. Coupling Phase Diagrams Thermochem., 2009, vol. 33, pp. 495-501.

28. M. Hillert and L. Höglund: Scr. Mater., 2006, vol. 54, pp. 1259-63.

29. J. Ågren: Acta Metall., 1989, vol. 37, pp. 181-9.

30. E.J. Seo, L. Cho, Y. Estrin, and B.C. De Cooman: Acta Mater., 2016, vol. 113, pp. 124-39. 